This is an author produced version of a paper published in Ecology.

This paper has been peer-reviewed and is proof-corrected, but does not include the journal pagination.

Citation for the published paper:

Wardle, David A.; Jonsson, Micael; Kalela-Brundin, Maarit; Lagerström, Anna; Bardgett, Richard D.; Yeates, Gregor W.; Nilsson, Marie-Charlotte.

(2012) Drivers of inter-year variability of plant production and decomposers across contrasting island ecosystems. Ecology. Volume: 93, Number: 3, pp 521-531.

http://dx.doi.org/10.1890/11-0930.1.

Access to the published version may require journal subscription.

Published with permission from: Ecological Society of America.

Epsilon Open Archive http://epsilon.slu.se 


\title{
Drivers of inter-year variability of plant production and decomposers across contrasting island ecosystems
}

\author{
DAVID A. WARDLE ${ }^{1}$, MICAEL JONSSON ${ }^{2}$, MAARIT KALELA-BRUNDIN ${ }^{3}$, ANNA \\ LAGERSTRÖM $^{1}$, RICHARD D. BARDGETT ${ }^{4}$, GREGOR W. YEATES ${ }^{5}$ AND MARIE- \\ CHARLOTTE NILSSON ${ }^{1}$
}

${ }^{1}$ Department of Forest Ecology and Management, Swedish University of Agricultural Sciences, SE901

83, Umeå, Sweden

${ }^{2}$ Department of Ecology and Environmental Science, Umeå University, 90187 Umeå, Sweden

${ }^{3}$ Museum of Forestry, Box 176, S921 23 Lycksele, Sweden

${ }^{4}$ Soil and Ecosystem Ecology Laboratory, Lancaster Environment Centre, Lancaster University, Lancaster LA1 4YQ, UK.

${ }^{5}$ PO Box 1758, Palmerston North 4440, New Zealand

Corresponding author: David A. Wardle

Phone: 00-46-90-7868471

Fax: 00-46-90-7868166

E-mail: david.wardle@svek.slu.se 
Abstract. Despite the likely importance of inter-year dynamics of plant production and

2 consumer biota for driving community- and ecosystem-level processes, very few studies have

3 explored how and why these dynamics vary across contrasting ecosystems. We utilized a well

4 characterized system of 30 lake islands in the boreal forest zone of northern Sweden across which

5 soil fertility and productivity vary considerably, with larger islands being more fertile and

6 productive than smaller ones. In this system we assessed the inter-year dynamics of several

7 measures of plant production and the soil microbial community (primary consumers in the

8 decomposer food web) for each of 9 years, and soil microfaunal groups (secondary and tertiary

9 consumers) for each of 6 of those years. We found that for measures of plant production and each of

10 the three consumer trophic levels, inter-year dynamics were strongly affected by island size. Further,

11 many variables were strongly affected by island size (and thus bottom-up regulation by soil fertility

12 and resources) for some years but none in others, most likely due to inter-year variation in climatic

13 conditions. For each of the plant and microbial variables for which we had 9 years of data, we also

14 determined the inter-year coefficient of variation $(\mathrm{CV})$, an inverse measure of stability. We found

15 that CVs of some measures of plant productivity were greater on large islands while those of other

16 measures were greater on smaller islands; CVs of microbial variables were unresponsive to island

17 size. We also found that the effects of island size on the temporal dynamics of some variables were

18 related to inter-year variability of macroclimatic variables. As such, our results show that the inter-

19 year dynamics of both plant productivity and decomposer biota across each of three trophic levels,

20 as well as the inter-year stability of plant productivity, differs greatly across contrasting ecosystems,

21 with potentially important but largely overlooked implications for community and ecosystem

22 processes. 
1 Key words: decomposers, ecosystem retrogression, inter-year variation, island size, net primary

2 productivity, soil fertility, stability, temporal variability

INTRODUCTION

5

6 Many ecosystems experience large differences in climatic conditions between years, which can

7 cause considerable inter-year variability in their net primary production (NPP) (Yang et al. 2008).

8 There is growing evidence that inter-year variability in NPP differs greatly both across vegetation

9 types and among biomes (Knapp and Smith 2001, Hui and Jackson 2006). Several studies have

10 focused on how the stability of NPP may be affected by plant community attributes, notably plant

11 diversity (Hooper et al. 2005, Ives and Carpenter 2007), and some of these have explicitly used

12 inter-year variation in NPP as an inverse measure of stability (e.g., Bai et al. 2004, Tilman et al.

13 2006, Bezemer and van der Putten 2007). There is also evidence that manipulation of soil resources

14 and resultant changes in plant community attributes can impact on inter-year NPP variability

15 (Grman et al. 2010). Further, a significant body of literature has developed on how species

16 interactions and compensatory dynamics among coexisting species influences temporal stability of

17 NPP (Ives and Carpenter 2007), some of which have explicitly considered inter-year variability of

18 NPP (Bai et al. 2004, Grman et al. 2010). However, there have been few attempts to understand the

19 drivers of inter-year variation in NPP across contrasting natural ecosystems, and the reasons for

20 why this variation differs among real ecosystems have seldom been addressed.

21 There is long-standing recognition that inter-year variation in consumer abundances can be

22 considerable for both aboveground (Pimm 1991) and belowground (Kampichler and Giessen 2005,

23 Berg and Bengtsson 2007) biota, which may reflect inter-year variability in climate and NPP. Our

24 knowledge of how and why inter-year variation of consumer organisms varies among contrasting 
1 ecosystems remains limited. Most relevant recent studies have focused on how stability of

2 consumer populations and communities may be related to consumer and/or producer diversity,

3 usually in experimentally synthesized communities (Ives and Carpenter 2007, Jiang and Pu 2009).

4 Some of these have explicitly explored how experimental manipulation of plant species diversity or

5 composition can influence inter-year variability of invertebrate communities both above- and

6 belowground (Wardle et al. 1999, Proulx et al. 2010, Haddad et al. 2011). The impact of most other

7 factors that vary among ecosystems on inter-year variability of consumer organisms remains little

8 explored, especially in natural ecosystems. However, those consumers that are regulated by bottom-

9 up control and therefore by their food supply are likely to show patterns of inter-year variability that

10 correspond to temporal shifts in NPP (Wardle et al. 1999, Proulx et al. 2010).

11 In the present study, we utilized a well characterized group of 30 forested lake islands in

12 northern Sweden to quantify inter-year dynamics of NPP and three consumer trophic levels in a

13 decomposer food web. These islands all have the same climate and parent material, but they vary

14 greatly in size and this in turn drives soil fertility and therefore vegetation composition and

15 productivity (Wardle et al. 1997, 2003). For each island we measured plant productivity over 9

16 years using three measures: tree litter fall, tree stem radial growth, and understory shrub production.

17 Measurements were also made of belowground basal consumers (microbes) over the 9 years, and of

18 secondary and tertiary consumers (microfauna) for 6 years. We used these data to test two related

19 hypotheses. Our first hypothesis was that the effects of island size (and thus soil resource

20 availability) on NPP and consumer trophic levels are not constant but instead varies among years.

21 This hypothesis tests if islands of different sizes display inherently different temporal dynamics,

22 which may or may not lead to differences in temporal variability or stability. Our second hypothesis

23 was that temporal temporal (inter-year) variability (an inverse measure of stability) of NPP and

24 consumer biota is lowest on the islands that have the highest soil fertility. This is in line with the 
1 prediction that enhanced ecosystem stability is often associated with higher productivity (Hooper et

2 al. 2005, Ives and Carpenter 2007). We further explored whether inter-year variation in the

3 relationship of NPP and soil microbes with island size could be explained by inter-year variation in

4 macroclimatic variables, to shed light on the mechanisms underpinning the effects of island size on

5 temporal dynamics. Through exploration of these data, we provide the first large-scale

6 demonstration of how inter-year dynamics in NPP and consumer organisms vary across contrasting

7 natural ecosystems that differ greatly in soil fertility, vegetation composition and productivity.

MATERIALS AND METHODS

Study system

13 The study system consists of 30 islands in lakes Hornavan and Uddjaure in northern Sweden

$14\left(65^{\circ} 55^{\prime} \mathrm{N}\right.$ to $66^{\circ} 09^{\prime} \mathrm{N} ; 17^{\circ} 43^{\prime} \mathrm{E}$ to $\left.17^{\circ} 55^{\prime} \mathrm{E}\right)$. The mean annual precipitation over the past 30 years is

$15750 \mathrm{~mm}$, and the mean temperature is $+13{ }^{\circ} \mathrm{C}$ in July and $-14{ }^{\circ} \mathrm{C}$ in January. All islands were

16 formed following the retreat of land ice about 9000 years ago. The only major extrinsic factor that

17 varies among islands is the history of lightning ignited wildfire, with larger islands having burned

18 more frequently than smaller islands because of their larger area to intercept lightning (Wardle et al.

19 1997, 2003, Jonsson and Wardle 2010). Previous studies on these islands have shown that as they

20 become smaller and time since fire increases, they enter a state of 'ecosystem retrogression' (Peltzer

21 et al. 2010) in which there is a reduction in soil fertility (notably a reduced availability of plant-

22 available nitrogen and phosphorus), plant biomass and ecosystem productivity, and an increase in

23 plant species diversity (Wardle et al. 1997, 2003, 2004, Lagerström et al. 2009). 
The islands were divided into three size classes with 10 islands per class: large ( $>1.0 \mathrm{ha})$,

2 medium (0.1-1.0 ha) and small $(<0.1 \mathrm{ha})$, with a mean time since last major fire of 585, 2180 and

33250 years, respectively (Wardle et al. 2003). The use of size classes in this way enables simple

4 statistical testing of interactive effects of island size with other factors (e.g., Wardle and Zackrisson

5 2005; Gundale et al. 2010). All islands burned at least 60 years ago (and up to 5350 years ago), and

6 so have not been subjected to differing fire disturbance regime for several decades prior to the

7 present study. The overstory vegetation of the island system is dominated by Pinus sylvestris,

8 Betula pubescens and Picea abies, which have their greatest relative biomass on large, medium and

9 small islands respectively. The ground layer vascular vegetation is dominated by the dwarf shrubs

10 Vaccinium myrtillus, V. vitis-idaea and Empetrum hermaphroditum, which have their greatest

11 relative biomass on large, medium and small islands respectively. Betula pubescens and V. myrtillus

12 are deciduous and the other species are all evergreen. We performed this study in the same plots as

13 Wardle et al. (2003) with one plot per island. Plots were approximately $10 \mathrm{~m}$ x $10 \mathrm{~m}$ and always

14 located at similar distances from the shore regardless of island size to prevent edge and

15 microclimatic effects from confounding the results (Wardle et al. 1997, 2003).

Aboveground measurements

19 We measured tree litter production with three permanent litter trays installed at ground level on

20 each island in August 1999 (described by Wardle et al. 2003); each tray has a collecting area of

$210.325 \mathrm{~m}^{2}$. Each August from 2000 to 2008 inclusive, all litter from each tray was collected and

22 hand-sorted into leaf or needle material for each tree species, and twigs. Any variation among

23 islands in litter decomposition in the trays between collection events is presumed to be negligible

24 (Wardle et al. 2003). Although decomposition of leaf litter in soil shows minor variation across 
1 island size classes (Wardle et al. 2003) this is less than two orders of magnitude lower than the

2 variation among islands in the amount of litter fall; further twig decomposition rates do not vary

3 among island size classes (Dearden et al. 2006). Additionally, litter in the trays is in contact with

4 fine draining plastic and not soil between litter fall and collection, which should significantly

5 impede losses due to decomposition between collection events. Litter dry weight was determined by

6 drying at $80^{\circ} \mathrm{C}$ for $24 \mathrm{~h}$. Litter fall data from these trays until 2002 is presented by Wardle et al.

7 (2003). We also measured radial stem growth of each of the three tree species on each island from

82000 to 2008 inclusive, as described by Wardle et al. (2003). During June 13-17 2009 we selected

9 five individuals of each tree species in each plot of between $8.0 \mathrm{~cm}$ and $15.0 \mathrm{~cm}$ diameter at breast

10 height. For each tree, one core of wood was sampled at breast height, and its radial growth for each

11 year from 2000 to 2008 inclusive was measured to the nearest 10 microns. Further, for each year a

12 weighted measure of radial growth of all species at the whole plot level was calculated by

13 weighting the mean radial growth of each species in that year by the proportion of the total tree

14 basal area that it constituted, using tree basal area data provided by Wardle et al. (2008).

15 We measured biomass and production of each of the three dominant shrub species $(E$.

16 hermaphroditum, V. myrtillus and V. vitis-idaea) in each plot as described by Wardle et al. (2003);

17 these three shrubs collectively account for over $98 \%$ of vascular plant biomass in the understory.

18 Each August from 2000 to 2008 inclusive, the point intercept method was used to determine the

19 total number of times the vegetation of each species was intercepted by a total of 200 downwardly

20 projected points located throughout the plot. The total number of intercepts for each species was

21 then converted to biomass per unit area through calibration equations (Wardle et al. 2003).

22 Concomitantly, twenty stems of each of the three shrub species were collected throughout the plot;

23 these were cut at ground level and the portion of the stem produced in that growing season (i.e.,

24 when shoot growth is actively taking place in May-July) was separated from the stem material 
1 produced in all preceding growing seasons. This was used to determine the proportion of biomass

2 present in each growing season (determined by point interception) that had been produced in that

3 year for each species, and when multiplied by biomass per unit area provides a measure of

4 productivity per unit area (Wardle et al. 2003). Shrub biomass and production data until 2002 is

5 presented by Wardle et al. (2003). Production of berries by two shrub species (E. hermaphroditum

6 and $V$. myrtillus) was also quantified by randomly placing a $0.5 \mathrm{~m} \mathrm{x} 0.5 \mathrm{~m}$ quadrat in four positions

7 throughout the plot, counting all the berries within the quadrat and determining their oven-dry

8 weight.

Belowground measurements

12 To quantify belowground biota, approximately 50 soil cores of humus (each $25 \mathrm{~mm}$ diameter, 10

13 cm deep) were collected from each plot every August from 2000 to 2008 inclusive and bulked

14 within the plot as described by Jonsson et al. (2009). For each sample, measurements were made of

15 microbial basal respiration (BR) and substrate-induced respiration (SIR; a relative measure of active

16 microbial biomass) as described by Wardle (1993). Briefly, a $10 \mathrm{~g}$ (dry weight) subsample of soil

17 was amended to $150 \%$ moisture content (dry weight basis), placed it in a $130 \mathrm{ml}$ airtight vessel, and

18 incubated at $22^{\circ} \mathrm{C}$. Evolution of $\mathrm{CO}_{2}$ between $1 \mathrm{~h}$ and $4 \mathrm{~h}$ was then determined, by injecting $1 \mathrm{ml}$

19 subsamples of headspace gas into an infrared gas analyser and used as a measure of BR.

20 Measurement of SIR (Anderson and Domsch 1978) was performed in the same way, but with

21 sample amendment of $100 \mathrm{mg}$ glucose when the incubation started (Wardle 1993).

22 Community data of soil microbes (i.e., primary consumers) was obtained for each sample by

23 measuring the composition of microbial phospholipid fatty acids (PLFAs) using the method of

24 Bligh and Dyer (1959), as modified by White et al. (1979) and Bardgett et al. (1996); different 
1 PLFAs represent different subsets of the soil microflora. For each soil, the abundance of each fatty

2 acid extracted was expressed as relative nmoles per g of dry soil using standard nomenclature

3 (Tunlid et al. 1989). The PLFA's used to represent bacteria were i-15:0, a-15:0, 15:0, i-16.0,

$4 \quad 16: 1 \omega 9, \mathrm{i}-17: 0, \mathrm{cy}-17: 0,17: 0,18: 1 \omega 9 \mathrm{c}, 18: 1 \omega 9 \mathrm{t}$, and cy-19:0, and 18:2 $\omega 6$ was used to represent

5 fungi. The PLFAs used for calculation of total branched PLFAs (indicative of gram positive

6 bacteria) were i-15:0, a-15:0, i-16:0 and i-17:0, while those used for determining total cyclic PLFAs

7 were cyc-17:0 and cyc-19:0.

$8 \quad$ For all soil samples collected from 2003 onwards, soil microfauna (nematodes, rotifers and

9 tardigrades) were extracted from a $100 \mathrm{~g}$ wet weight subsample, using a variant of the tray method

10 (Yeates 1978). Microfauna were counted live at $40 \mathrm{x}$ magnification before fixing the suspension by

11 the addition of an equal volume of boiling $8 \%$ formaldehyde. Subsequently an average of 122

12 nematodes per sample were identified to nominal genus following Yeates et al. (1993) and placed

13 into feeding groups, namely bacterial-feeding, fungal-feeding, and top predatory. The top predatory

14 nematodes are tertiary consumers which feed on other nematodes, and all other microfaunal groups

15 are secondary consumers which feed on microbes. Nematode data for the years 2006 and 2007 are

16 presented by Jonsson et al. (2009).

\section{Data analysis}

20 To test our first hypothesis, we analyzed each plant and decomposer response variable by Repeated

21 Measures ANOVA, testing for the effects of island size class, year, and their interaction. A

22 significant interaction was taken to mean that the effect of island size on the response variable

23 differed among years. When interaction terms were significant, one way ANOVAs were then used

24 to assess the effect of island size on that response variable separately for each year. To test our 
1 second hypothesis, for each plant and microbial response variable (for which we had 9 years of

2 data) we calculated the inter-year Coefficient of Variation (CV; standard deviation / mean) for each

3 island. Values of CVs across time are frequently used as scale-independent measures of temporal

4 variability (Knapp \& Smith 2001) or the reciprocal of stability (Pimm 1991). We did not assess

5 CVs for microfauna because 6 years of data was deemed to provide insufficient power for

6 determining how $\mathrm{CV}$ varies in relation to island size. The use of 9 years data for assessing CVs is

7 on par with other comparable studies investigating inter-year variability of plant productivity

8 (Tilman et al. 2006), ecosystem fluxes (Polley et al. 2008) and invertebrate taxa (Proulx et al. 2010,

9 Haddad et al. 2011). One-way ANOVA was used to determine the effect of island size class on the

$10 \mathrm{CV}$. Values of CV were not determined for variables presented as percentages. Data were

11 transformed as needed to satisfy assumptions of parametric analyses, and in the case of CVs, after

12 rather than before CVs were calculated.

13 To gain insights into how macroclimate variation among years influences inter-year

14 variation in our response variables, we also performed analyses for which each of the 9 years was

15 represented as a separate data point, and did not consider microfauna for which we had data for too

16 few years. For each plant and microbial response variable, this involved determining Coefficients of

17 Determination $\left(R^{2}\right)$ values across the 9 years between the within-year strength of its relationship

18 with island size (quantified as Pearson's correlation coefficient $r ; n=30$; island size log-

19 transformed) and macroclimatic variables. The macroclimatic variables used were mean

20 temperature and total precipitation for each of five three-month periods preceding measurement of

21 the response variable (i.e., the previous 3 months, 4-6 months, 7-9 months, 10-12 months, and 13-

2215 months), using data from the Arjeplog climate station (centred in the study area) provided by the

23 Swedish Meteorological Service (SMHI). Because for each response variable we determined 10 
1 separate $R^{2}$ values, we used a Bonferroni correction and thus set $\alpha$ at 0.005 (i.e., $R^{2}=0.699$ ) as our

2 criterion for identifying statistical significance at $P=0.05$.

\section{RESULTS}

6 For the litter tray data over the entire 9 year period, most variables representing quantity of litter fall

7 were affected by island size and least on the small islands; the only exceptions were leaf litter

8 production of B. pubescens and P. abies (Appendix A). The ratio of twig to total litter fall was

9 significantly affected by island size (through being greatest on small islands), while the ratio of

10 deciduous to total leaf litter fall was unaffected (Fig. 1; Appendix A). There were significant

11 interactive effects of island size with time for total and leaf litter fall (Fig. 1, Appendix A), and for

12 litter fall for conifers and P. abies (Appendix A), with highly significant effects of island size

13 during some years but not others. No significant interactive effects occurred for litter fall of $P$.

14 sylvestris or B. pubescens leaves, or for twigs ( $P$ always $>0.05$; Appendix A). Significant

15 interactive effects occurred for ratios of deciduous to total leaf litter, and twig to total litter (Fig. 1;

16 Appendix A), with island size effects being significant for 3 out of 9 years in both cases. Further,

17 for most litter fall variables, temporal variability (i.e., CV) across years was significantly affected

18 by island size through being greatest on small islands, the only exceptions being leaf litter fall for $P$.

19 abies and B. pubescens (Table 1).

20 For the tree core data, P. sylvestris radial growth was affected by island size over the 9 year

21 period, and was greatest on the small islands (Appendix A). Island size had no effect on radial

22 growth on the other two species, or for the weighted average measure of radial growth at the whole

23 plot level (Appendix A). Further, there were no significant interactions between island size and time, 
1 or island size effects on temporal variability (i.e., CV), for any variable derived from the tree core

2 data (Table 1).

Total dwarf shrub shoot production and biomass over the 9 years were significantly affected

4 by island size and were least on small islands (Fig. 2; Appendix B). Shoot production of each

5 species was also responsive to island size, with V. myrtillus, V. vitis-idaea and E. hermaphroditum

6 being most productive on large, medium and small islands respectively (Fig. 2; Appendix B). For

7 each species, total shoot biomass showed the same response to island size as did production

8 (Appendix B). The ratio of deciduous to total shoot production was significantly greater on large

9 than on small or medium islands (Appendix B). Berry production by number was significantly

10 affected by island size for E. hermaphroditum (and was greatest on small islands) but not for $V$.

11 myrtillus (Fig. 2; Appendix B); for both species berry biomass production showed the same trend as

12 for number (data not presented). There were significant interactive effects between island size and

13 time for total shoot production and biomass, and for E. hermaphroditum shoot production and berry

14 number (Fig. 2). Interactive effects also occurred for mass of $E$. hermaphroditum shoots $\left(F_{16,216}=\right.$

$151.78, P=0.035)$ and berries $\left(F_{16,216}=3.17, P<0.001\right)$ and $V$. vitis-idaea shoots $\left(F_{16,216}=1.98, P=\right.$

160.016 ) (data not presented). No other interaction terms were significant at $P=0.05$. Across the 9

17 years, temporal variability was significantly affected by island size for total shoot biomass, and $E$.

18 hermaphroditum shoot and berry production, but not for the other variables (Table 2), through

19 being least on small islands in each case.

20 Over the 9 years, all microbial activity and biomass variables except fungal PLFA were

21 significantly affected by island size and lowest on small islands (Appendix C). The ratio of fungal

22 to total microbial (bacterial + fungal) PLFAs was also significantly affected by island size through

23 being greater on smaller islands (Fig. 3; Appendix C). There were significant interactive effects

24 between island size and time for microbial BR, SIR and the ratio of fungal to total microbial PLFAs 
1 (but not for the other microbial variables), through effects of island size being highly significant for

2 some years but not for others (Fig. 3, Appendix C). There were no microbial variables for which

3 temporal variability was influenced by island size (Appendix D).

$4 \quad$ Over the 6 years for which microfauna were measured, all microbe-feeding faunal groups

5 (i.e., secondary consumers) were significantly affected by island size, while the top predatory

6 nematodes (i.e., tertiary consumers) were not (Fig. 4; Appendix E). For all microbe-feeding groups,

7 abundances were greatest for medium-sized islands. Further, for microbe-feeding and bacterial-

8 feeding nematodes numbers were significantly smaller for small than for medium or large islands,

9 and the ratio of fungal feeding to total microbial-feeding nematodes was greatest on the small

10 islands (Appendix E). There were significant interactive effects of island size and time on microbe-

11 feeding nematodes, tardigrades and top predatory nematodes (Fig. 4), and on bacterial-feeding

12 nematodes (which showed the same responses as microbe feeding nematodes for which they

13 constituted most of the individuals; data not presented). There were no interactive effects on any

14 other microfaunal variables (Appendix E).

15 The Coefficient of Determination $\left(R^{2}\right)$ measures across years revealed that for plant

16 production variables, the strength of island size effect was most closely related to the temperature of

17 the previous summer (June to August of the previous year, or 13-15 months prior to the time of

18 production measurement). There were two variables for which these relationships were highly

19 significant even when Bonferroni corrections were applied, i.e, total shrub biomass and radial

20 growth of P. abies (Appendix F). In both cases effects of island size on production showed strong

21 linear declines with increasing temperature. 
1 In this study, we clearly show that declining soil fertility with island size, and therefore reduced

2 quantity and quality of plant-derived resource inputs (Wardle et al. 1997, 2003), influenced several

3 measures for both primary and secondary (but not tertiary) consumers in the soil food web which

4 were lowest on the small islands. We also showed that as island size declined, tree litter fall

5 contained a higher proportion of twigs, and the understory contained a lower proportion of

6 deciduous species and a greater proportion of E. hermaphroditum; these changes have all previously

7 been shown to cause impairment of microbial decomposer activity on small islands

8 (Wardle and Zackrisson 2005, Dearden et al. 2006). Further, the importance of the fungal-based

9 relative to the bacterial-based energy channel declined with island size for both the primary and

10 secondary consumer trophic levels (as revealed by ratios of bacterial to total microbial PLFAs, and

11 bacterial feeding to total microbial feeding nematodes), indicative of poorer resource quality

12 associated with less fertile conditions (Williamson et al. 2005, Eskelainen et al. 2009). Previous

13 studies have shown variable effects of top down versus bottom up forces in regulating different

14 trophic levels of the soil food web (Mikola and Setälä 1998, Wardle et al. 1999, Scherber et al.

15 2010). However, in our study, the primary and secondary consumer trophic levels across all years

16 were strongly responsive to variation in plant-derived resources across island size classes, and

17 therefore bottom-up regulation.

18 Because we made measurements for all response variables annually for 6 or 9 years, our

19 study enables examination of inter-year variation of their relationships with island size. There were

20 interactive effects between island size and year on several variables that describe the quality and

21 quantity of plant derived resource inputs, and on organisms in each of three consumer trophic levels.

22 This means that island size effects on these variables differed among years, and indeed several

23 response variables within each trophic level showed strong responses to island size in some years

24 but not others, supporting our first hypothesis (Figs. 1-4). This means that islands differing in soil 
1 fertility and productivity show inherently different temporal dynamics across years. A likely

2 explanation is that some climatic factors which differ among years dictate whether variation in

3 resources among islands actually influences plant production and belowground consumer organisms.

4 This finding highlights that full assessment of how plant production or consumer groups respond to

5 underlying environmental gradients requires measurements for multiple years to capture the inter-

6 year variation of this response. It also helps explain why strong bottom-up effects of resources on

7 key decomposer groups have been shown in some studies but not others (Mikola and Setälä 1998,

8 Wardle 2002). Further, it is apparent from Figs 1-4 that island size does not necessarily have its

9 strongest effects on consumer trophic levels during the same years that it has its strongest effect on

10 plant variables. As an example, microbe feeding nematodes had much greater abundance in 2004

11 and 2007 than in the other years (Fig. 4), even though those years were not characterized by

12 correspondingly greater tree litter and shrub production (Figs. 1, 2). It is also apparent for the

13 microfaunal data that island size effects are often strongest for those years in which abundance is

14 greatest. These data are consistent with previous studies showing that microfaunal abundances vary

15 greatly over time in response to factors that are not directly related to plant productivity, such as

16 short term moisture dynamics (Bakonyi et al. 2007, Jonsson et al. 2009), and therefore respond to

17 gradients of resource availability (and thus experience bottom-up control) only when those factors

18 allow for high abundances.

19 Whenever a given response variable is influenced by the interactive effects of island size

20 and year, it is also possible for its inter-year variability to be affected by island size. Tree and leaf

21 litter fall had higher CVs on small than large islands, reflecting litter production data for a dominant

22 tree species (P. sylvestris). In contrast, CVs for tree radial growth and total dwarf shrub production

23 were unresponsive to island size, while CVs of total shoot mass, and of E. hermaphroditum shoot

24 and berry production, were larger on large islands. These results highlight that CVs of different 
1 measures of plant productivity respond to island size in different ways that are not always consistent

2 with theories predicting greater temporal stability in more productive ecosystems (Hooper et al.

3 2005), or with our second hypothesis. Further, NPP and plant species diversity are negatively

4 correlated across islands with greatest diversity on small islands (Wardle et al. 2008), and there was

5 no evidence for any measure of stability of NPP (except for one shrub species) being greater on the

6 more diverse islands. These results are inconsistent with several studies performed on

7 experimentally synthesized communities (Tilman et al. 2006, Ives and Carpenter 2007, Proulx et al.

8 2010) but agree with other studies in naturally assembled communities showing that plant diversity

9 effects on stability can be minor and overridden by other factors such as soil fertility and vegetation

10 composition (Wardle et al. 1999, Bezemer and van der Putten 2006, Grman et al. 2010). Further,

11 our results provide no evidence for CVs of microbial variables being responsive to island size,

12 despite there being interactive effects between island size and year for BR, SIR and fungal to

13 bacterial ratios.

14 For each of our response variables, we also explored underlying climatic factors that could

15 explain inter-year variation in the effect of island size on plant and microbial variables, using each

16 of the 9 years as separate data points. For some variables (notably shrub biomass; radial growth of

17 P. abies trees), this revealed that strong effects of island size on some variables occurred only in

18 years when the previous summer was cool, and that increasing summer temperatures eliminates

19 their responsiveness to inter-island variation in soil fertility. We recognize that testing relationships

20 across years has limitations because of the number of independent data points available (using 9

21 years as separate data points requires $R^{2}>0.699$ to be significant at $P=0.05$ following Bonferroni

22 correction), and that these tests are therefore conservative. Nevertheless they do provide evidence

23 that inter-year variation in the effects of island size on at least some response variables is driven by

24 inter-year variation in extrinsic factors. While several previous studies have tested for relationships 
1 between inter-year variation in biotic and climatic variables (Knapp and Smith 2001, Fang et al.

2 2001, Hui and Jackson 2006), our analyses also provide some evidence that that these relationships

3 can themselves vary across contrasting ecosystems that differ in soil fertility.

$4 \quad$ In sum, our results provide evidence of large differences in inter-year dynamics among

5 contrasting island ecosystems for measures of ecosystem productivity, and each of three

6 belowground trophic levels. Further, for measures of ecosystem production, this translates into

7 some differences among island size classes in temporal variability and therefore stability. These

8 results have several implications. First, they offer insights about ecological effects of changes in

9 soil fertility associated with long-term ecosystem succession and retrogression. Several recent

10 studies have considered how ecosystem retrogression may affect ecosystem processes and

11 consumers (Wardle et al. 2004, Peltzer et al. 2010), and our results provide evidence that not just

12 their mean values, but also their temporal dynamics change greatly as retrogression proceeds.

13 Second, they show that relationships of both NPP and consumer trophic levels with basal resource

14 availability (notably soil fertility) are not constant, and that the extent of bottom-up control differs

15 greatly between years, through being detectable in some years but not others. They also highlight

16 that inter-year variation in effects of soil fertility may be driven by climate; for two plant variables

17 we found that strong effects of island size disappeared in years following warmer summers. Third,

18 they show that temporal dynamics of different trophic levels may be driven by different factors. The

19 inter-year dynamics across island size classes for secondary and tertiary consumers did not match

20 those of NPP, indicating some decoupling between the aboveground and belowground subsystems

21 (Wardle 2002). Finally, they contribute to our understanding of the temporal dynamics of

22 ecosystem processes. Earlier work in this system has shown island size to affect both ecosystem

23 inputs of plant derived $\mathrm{C}$ and losses of $\mathrm{C}$ through decomposition (Wardle et al. 2003). The present

24 study extends these findings by revealing that inter-year dynamics of plant derived $\mathrm{C}$ input and loss 
1 of $\mathrm{CO}_{2}-\mathrm{C}$ through soil respiration are also highly responsive to island size. Further knowledge of

2 the drivers of inter-year dynamics of these $\mathrm{C}$ fluxes and the biotic interactions that underpin them

3 across contrasting ecosystems therefore has the potential to contribute to our understanding of the

4 dynamics of $\mathrm{C}$ exchange between terrestrial ecosystems and the atmosphere (Polley et al. 2008).

\section{ACKNOWLEDGEMENTS}

8 We thank Nils Anthes, Kai Altgott, Mark Blackburn, Karen Boot, Phil Hobbs, Abdulmajid

9 Mahomoud, Gaye Rattray, Natasha Rodda, Kate Orwin and Aron Sandling for field and/or

10 laboratory help, Kelley Gundale for drafting the figures, an anonymous reviewer for helpful

11 comments, and the Swedish Research Council (Vetenskapsrådet) for funding the study.

\section{REFERENCES}

15 Anderson, J. P. E. and K. H. Domsch. 1978. A physiologically active method for the quantification of microbial biomass in soil. Soil Biology and Biochemistry 10: 215-221.

17 Bai, Y. F., H. G. Han, J. G. Wu, Z. Z. Chen and H. H. Li. 2004. Ecosystem stability and compensatory effects in the Inner Mongolial grassland. Nature 431: 181-184.

19 Bakonyi, G., et al. 2007. Soil nematode community structure as affected by temperature and moisture in a temperate semiarid shrubland. Applied Soil Ecology 37: 31-40.

21 Bardgett, R. D., P. J. Hobbs and Å. \& Frostegård. 1996. Changes in the structure of microbial communities following reductions in the intensity and management of an alpine grassland. Biology and Fertility of Soils 22: 261-264. 
1 Berg, M. P. and J. Bengtsson. 2007. Temporal and spatial variability in soil food web structure. Oikos 116: 1789-1804.

3 Bezemer, T. H. and W. H. van der Putten. 2007. Diversity and stability in plant communities. $4 \quad$ Nature 446: E6-E7.

5 Bligh, E. G. and W. G. Dyer. 1959. A rapid method of total lipid extraction and purification. Canadian Journal of Biochemistry and Physiology 37: 911-917.

7 Dearden, F. M., H. Dehlin, D. A. Wardle and M.-C. Nilsson. 2006. Changes in the ratio of twig to foliage in litterfall and consequences for decomposition across a long-term fire-induced chronosequence. Oikos 115: 453-462.

10 Eskelinen, A., S. Stark and M. Mannisto. 2009. Links between plant community composition, soil 11 organic matter quality and microbial communities in contrasting tundra habitats. Oecologia 116: $113-123$.

13 Fang, J., S. Piao, Z. Tang, C. Peng and W. Ji. 2001. Interannual variability in net primary $14 \quad$ production and precipitation. Science 293: 1723a.

15 Grman, E., J. A. Lau, D. R. Schoolmaster and K. L. Gross. 2010. Mechanisms contributing to stability in ecosystem function depend on environmental context. Ecology Letters 13: 1400-

18 Gundale, M. J., D. A. Wardle and M.-C. Nilsson. 2010. Vascular plant removal effects on biological $\mathrm{N}$ fixation vary across a boreal forest island gradient. Ecology 91: 1704-1714.

20 Haddad, N. M., G. M. Crutsinger, K. Gross, J. Harstaad and D. Tilman. 2011. Plant diversity and the stability of food webs. Ecology Letters 14: 42-46.

22 Hooper, D. U., et al. 2005. Effects of biodiversity on ecosystem functioning: a consensus of current knowledge and needs for future research. Ecological Monographs 75: 3-35. 
1 Hui, D. F. and R. B. Jackson. 2006. Geographical and interannual variability in biomass partitioning in grassland ecosystems: a synthesis of field data. New Phytologist 169: 85-93.

3 Ives, A. R. and S. R. Carpenter. 2007. Stability and diversity of ecosystems. Science 317: 58-62.

4 Jiang, L. and Z. Pu. 2009. Different effects of species diversity on temporal stability in single$5 \quad$ trophic and multitrophic communities. American Naturalist 174: 651-659.

6 Jonsson, M. and D. A. Wardle. 2010. Structural equation modelling reveals plant-community

7 drivers of carbon storage in boreal forest ecosystems. Biology Letters 6: 116-119.

8 Jonsson, M., G. W. Yeates and D. A. Wardle. 2009. Patterns of invertebrate density and taxonomic

9 richness across gradients of area, isolation, and vegetation diversity in a lake-island system.

$10 \quad$ Ecography 32: 963-972.

11 Kampichler, C. and V. Giessen. 2005. Temporal predictability of soil microarthropod communities 12 in temperate forests. Pedobiologia 49: 41-50.

13 Knapp, A. K. and M. D. Smith, M. D. 2001. Variation among biomes in temporal dynamics of 14 aboveground primary production. Science 291: 481-484.

15 Lagerström, A., C. Esberg, D. A. Wardle and R. Giesler. 2009. Soil phosphorus and microbial 16 response to a long-term wildfire chronosequence in northern Sweden. Biogeochemistry 95: $17 \quad 199-231$.

18 Mikola, J. and H. Setälä. 1998. Productivity and trophic-level biomasses in a microbial-based soil 19 food web. Oikos 82: 158-168.

20 Peltzer, D. A., et al. 2010. Understanding ecosystem retrogression. Ecological Monographs 80: 509$21 \quad 529$.

22 Pimm, S.L. 1991. The Balance of Nature? Ecological Issues in the Conservation of Species and 23 Communities. The University of Chicago Press, Chicago, USA. 
1 Polley, H. W., A. B. Frank, J. Sanabria and R. L. Phillips. 2008. Interannual variability in carbon

4 Proulx, R., et al. 2010. Diversity promotes temporal stability across levels of ecosystem dioxide fluxes and flux-climate relationships on grazed and ungrazed northern mixed.grass prairie. Global Change Biology 14: 1620-1632. organization in experimental grasslands. PLoS ONE 5: e13882.

Scherber, C., et al. 2010. Bottom-up effects of plant diversity on multitrophic interactions in a biodiversity experiment. Nature 468: 553-556.

Tilman, D., P. B. Reich and J. M. H. Knops. 2006. Biodiversity and ecosystem stability in a decadelong grassland experiment. Nature 441: 629-632.

Tunlid, A., H. A. W. Hoitink and C. Low. 1989. Characterisation of bacteria that suppress Rhizoctonia damping-off in bark compost media by analysis of fatty acid biomarkers. Appl. Environmental Microbiology 55: 1368-1374.

Wardle, D.A. 1993. Changes in the microbial biomass and metabolic quotient during leaf litter succession in some New Zealand forest and scrubland ecosystems. Functional Ecology 7: 346355.

Wardle, D. A. 2002. Communities and Ecosystems: Linking the Aboveground and Belowground Components. Princeton University Press, Princeton, U.S.A.

Wardle, D. A., et al. 1999. Plant removals in perennial grassland: vegetation dynamics, decomposers, soil biodiversity and ecosystem properties. Ecological Monographs 69: 535-568.

Wardle, D. A. and O. Zackrisson. 2005. Effects of species and functional group loss on island ecosystem properties. Nature 435: 806-810.

Wardle, D. A., O. Zackrisson, G. Hörnberg and C. Gallet. 1997. The influence of island area on ecosystem properties. Science 277: 1296-1299. 
1 Wardle, D. A., G. Hörnberg, O. Zackrisson, M. Kalela-Brundin and D. A. Coomes. 2003. Long term effects of wildfire on ecosystem properties across an island area gradient. Science 300: 972-975.

3 Wardle, D. A., L. R. Walker and R. D. Bardgett. 2004. Ecosystem properties and forest decline in 4 contrasting long-term chronosequences. Science 305: 509-513.

5 Wardle, D. A., R. D. Bardgett, L. R. Walker, D. A. Peltzer and A. Lagerström. 2008. The response

6 of plant diversity to ecosystem retrogression: evidence from contrasting long-term

$7 \quad$ chronosequences. Oikos 117: 93-103

8 White, D. C., W. M. Davis and J. S. Nikels. 1979. Determination of the sedimentary microbial 9 biomass by extractable lipid phosphate. Oecologia 40: 51-62.

10 Williamson, W. M., D. A. Wardle and G. W. Yeates. 2005. Changes in soil microbial and nematode 11 communities during ecosystem retrogression across a long term chronosequence. Soil 12 Biology and Biochemistry 37: 1289-1301.

13 Yang, Y. H., J. Y. Fang, W. H. Ma and W. Wang. 2008. Relationship between variability in 14 aboveground net primary production and precipitation in global grasslands. Geophysical $15 \quad$ Research Letters 35: L23710.

16 Yeates, G. W. (1978) Populations of nematode genera in soils under pasture. I. Seasonal dynamics 17 in dryland and irrigated pasture on a southern yellow-grey earth. N. Z. J. Agr. Res., 21, 321$18 \quad 330$.

19 Yeates, G. W., Bongers, T., de Goede, R. G. M., Freckman, D. W. \& Georgeiva, S. S. (1993)

20 Feeding habits in soil nematode families and genera - an outline for soil ecologists. J. $21 \quad$ Nematol., 25, 315-331. 
TABLE 1. Inter-year Coefficients of Variation (standard deviation / mean) \pm SE for tree litterfall measured in litter trays and tree radial growth data across a nine-year period (2000-2008) in relation to island size class (small, medium and large).

Response variable Small islands Medium islands Large islands $\quad F(P)$

$\begin{array}{lllll}\text { Total (leaf + twig) } \quad 0.468 \pm 0.075 \mathrm{a} & 0.265 \pm 0.028 \mathrm{~b} & 0.240 \pm 0.026 \mathrm{a} & 8.2(0.003)\end{array}$

litter

$\begin{array}{lllll}\text { Total leaf litter } \quad 0.401 \pm 0.031 \mathrm{a} & 0.254 \pm 0.030 \mathrm{~b} & 0.218 \pm 0.027 \mathrm{~b} & 10.7(<0.001)\end{array}$

Total coniferous leaf $\quad 0.638 \pm 0.082$ a $\quad 0.367 \pm 0.350 \mathrm{~b} \quad 0.342 \pm 0.461 \mathrm{~b} \quad 10.1(<0.001)$ litter

$\begin{array}{lclll}\text { Pinus leaf litter } & 1.173 \pm 0.403 \mathrm{a} & 0.452 \pm 0.109 \mathrm{~b} & 0.319 \pm 0.037 \mathrm{~b} & 6.5(<0.001) \\ \text { Picea leaf litter } & 0.742 \pm 0.797 \mathrm{a} & 0.769 \pm 0.157 \mathrm{a} & 0.714 \pm 0.400 \mathrm{a} & 2.0(0.157) \\ \text { Betula leaf litter } & 0.451 \pm 0.050 \mathrm{a} & 0.367 \pm 0.065 \mathrm{a} & 0.348 \pm 0.089 \mathrm{a} & 1.8(0.247) \\ \text { Total twig litter } & 1.012 \pm 0.124 \mathrm{a} & 0.650 \pm 0.064 \mathrm{~b} & 0.779 \pm 0.092 \mathrm{ab} & 4.1(0.028) \\ \text { Pinus radial tree } & 0.180 \pm 0.021 \mathrm{a} & 0.172 \pm 0.019 \mathrm{a} & 0.140 \pm 0.010 \mathrm{a} & 1.5(0.252)\end{array}$
growth

$\begin{array}{lllll}\text { Picea radial tree } \quad 0.182 \pm 0.014 \text { a } & 0.220 \pm 0.022 \text { a } & 0.201 \pm 0.024 \text { a } & 0.9(0.441)\end{array}$ growth

Betula radial tree $\quad 0.323 \pm 0.040$ a $\quad 0.308 \pm 0.018$ a $\quad 0.321 \pm 0.024$ a $\quad 0.1(0.939)$ growth

Degrees of freedom for $F$-values derived from ANOVA are 2, 27; all ANOVAs except for radial growth data performed on In-transformed data. Within each row, mean or CV values followed by the same letter are not significantly different at $P=0.05$ (Tukey's test). 
TABLE 2. Inter-year Coefficients of Variation (standard deviation / mean) $\pm \mathrm{SE}$ for understory shrub biomass and production data measured over a nine-year period (2000-2008) in relation to island size class (small, medium and large).

Response variable $\quad$ Small islands $\quad$ Medium islands Large islands $\quad F(P)$

Total shrub shoot

$0.107 \pm 0.018 \mathrm{~b} \quad 0.145 \pm 0.010 \mathrm{ab}$

$0.156 \pm 0.013 \mathrm{a}$

$4.2(0.026)$

biomass

Total shrub shoot

$0.169 \pm 0.026 \mathrm{a} \quad 0.186 \pm 0.013 \mathrm{a}$

$0.197 \pm 0.014 \mathrm{a}$

$0.8(0.447)$

production

V. myrtillus shoot

$0.459 \pm 0.085 \mathrm{a} \quad 0.412 \pm 0.066 \mathrm{a}$

$0.306 \pm 0.025 \mathrm{a}$

$1.5(0.235)$

production

V. vitis-idaea shoot

$0.246 \pm 0.028$ a $\quad 0.267 \pm 0.028 \mathrm{a}$

$0.294 \pm 0.026 \mathrm{a}$

$0.9(0.429)$

production

Empetrum shoot

$0.302 \pm 0.034 \mathrm{~b} \quad 0.683 \pm 0.081 \mathrm{a}$

$0.581 \pm 0.087 \mathrm{a}$

$9.4(<0.001)$

production

V. myrtillus berry

$1.099 \pm 0.122 \mathrm{a} \quad 1.245 \pm 0.186 \mathrm{a}$

$0.883 \pm 0.057 \mathrm{a}$

$1.8(0.193)$

production (numbers)

Empetrum berry

$0.948 \pm 0.127 \mathrm{~b} \quad 1.623 \pm 0.168 \mathrm{a}$

$1.262 \pm 0.193 \mathrm{ab}$

$4.5(0.021)$

production (numbers)

Degrees of freedom for $F$-values derived from ANOVA are 2, 27; all ANOVAs performed on $I n$ transformed data. Within each row, mean or CV values followed by the same letter are not significantly different at $P=0.05$ (Tukey's test). 


\section{FIGURE LEGENDS}

FIG 1. Tree litterfall data over a 9 year period (2000-2008) for three island size classes: small (O), medium $(\square)$ and large $(\triangle) . F$ values (in top left of each panel) are from Repeated Measures ANOVA; $\mathrm{S}=$ island size (2, 27 degrees of freedom; d.f.), $\mathrm{T}=$ Time (8, 216 d.f.), and $\mathrm{S} \times \mathrm{T}$ (16, 216 d.f.). For each year, significance of island size effect is derived from one-way ANOVA. Significances are shown by: ${ }^{*} P<0.05 ;{ }^{*} P<0.01$; $* * * P<0.001$; NS $P>0.05$. All ANOVAs for the top two panels were performed on $\ln (\mathrm{X})$-transformed data. Error bars are Standard Errors.

FIG 2. Total shrub shoot biomass and production, and Empetrum shoot and berry production over a 9 year period (2000-2008) for three island size classes: small (O), medium ( $\square$ ) and large $(\triangle) . F$ values (in top left of each panel) are from Repeated Measures ANOVA; $S=$ island size (2, 27 degrees of freedom; d.f.), $\mathrm{T}=$ Time (8, 216 d.f.), and $\mathrm{S}$ x T (16, 216 d.f.). For each year, significance of island size effect is derived from one-way ANOVA. Significances are shown by: $* P<0.05 ; * * P<0.01 ; * * * P<0.001$; NS $P>0.05$. All ANOVAs were performed on $\ln (\mathrm{X})-$ transformed data. Error bars are Standard Errors.

FIG 3. Soil microbial variables (basal respiration, substrate-induced respiration as a measure of relative microbial biomass, and the ratio of fungal to fungal + bacterial PLFAs) over a 9 year period (2000-2008) for three island size classes: small (O), medium ( $\square$ ) and large ( $\triangle$ ). F values

(in top left of each panel) are from Repeated Measures ANOVA; S = island size (2, 27 degrees of freedom; d.f.), T = Time (8, 216 d.f.), and S x T (16, 216 d.f.). For each year, significance of island size effect is derived from one-way ANOVA. Significances are shown by: ${ }^{*} P<0.05$; $* * P<0.01 ; * * * P<0.001 ;$ NS $P>0.05$. Error bars are Standard Errors. 
FIG 4. Soil microfauna belonging to the secondary consumer trophic level (microbe-feeding nematodes and tardigrades) and tertiary consumer level (predatory nematodes) over a 6 year period (2003-2008) for three island size classes: small (O), medium ( $\square$ ) and large ( $\triangle$ ). $F$ values (in top left of each panel) are from Repeated Measures ANOVA; $\mathrm{S}=$ island size (2, 27 degrees of freedom; d.f.), $\mathrm{T}=$ Time (5, 135 d.f.), and S x T (10, 135 d.f.). For each year, significance of island size effect is derived from one-way ANOVA. Significances are shown by: ${ }^{*} P<0.05$; $* * P<0.01 ; * * * P<0.001$; NS $P>0.05$. All ANOVAs were performed on $\ln (\mathrm{X})$-transformed data. Error bars are Standard Errors. 

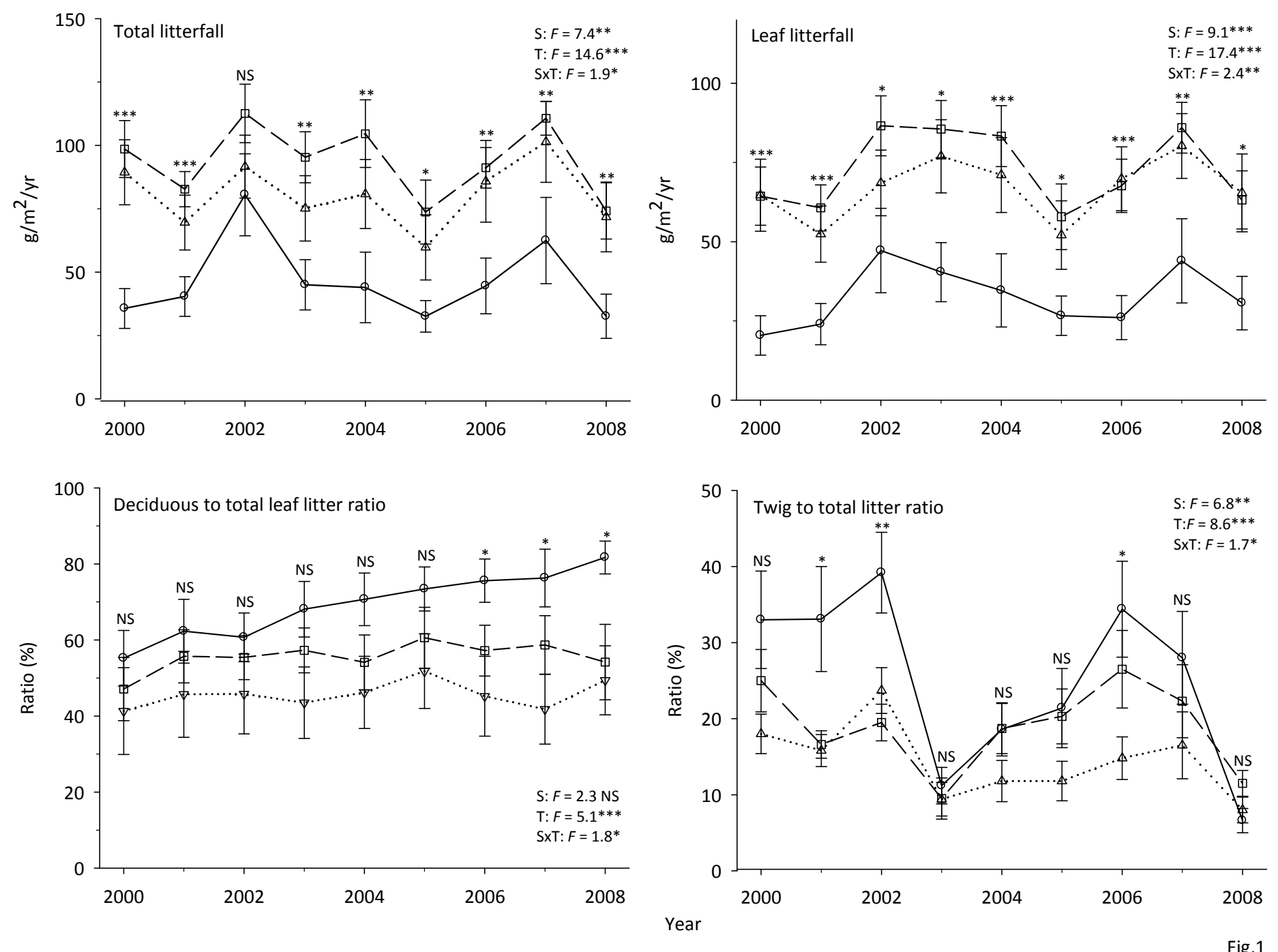

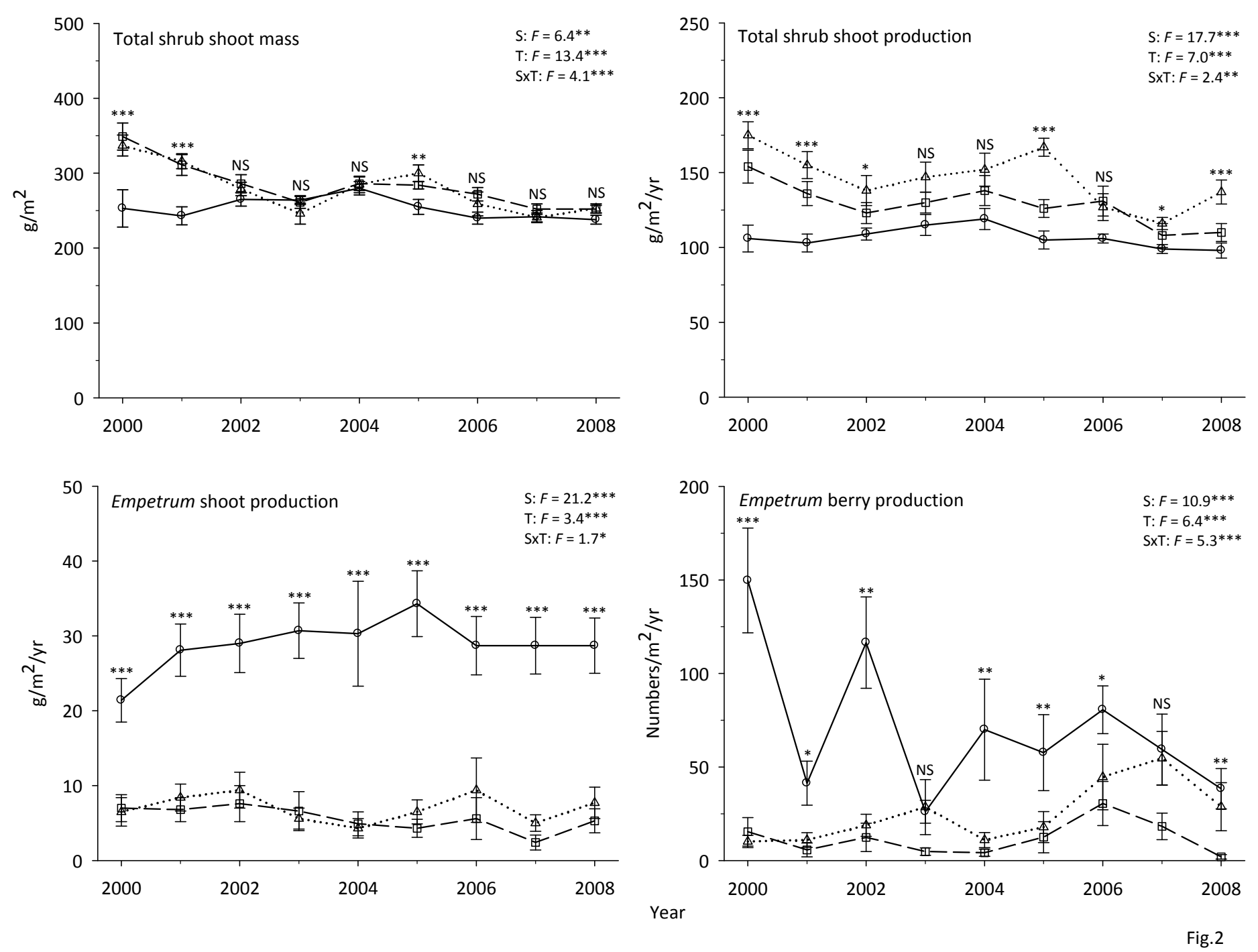

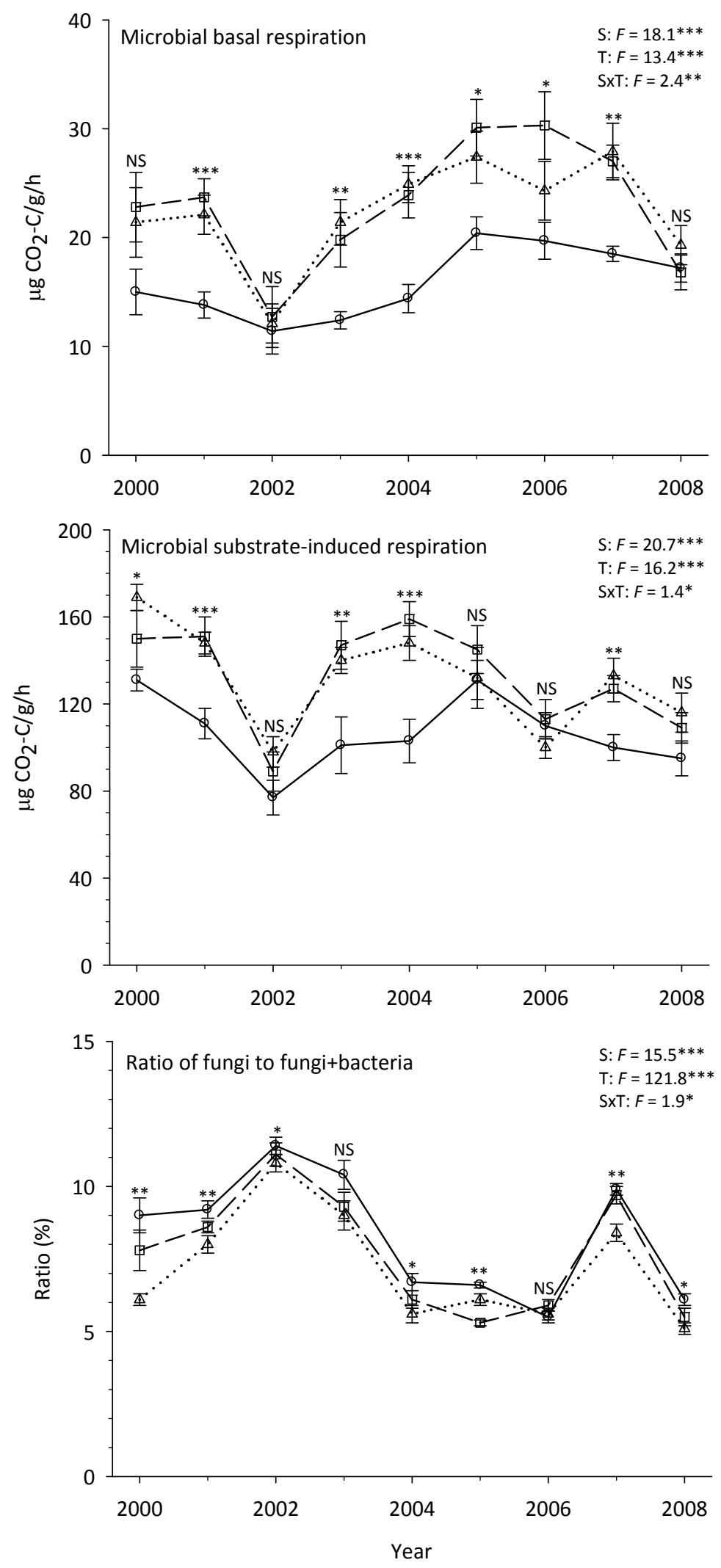

Fig.3 

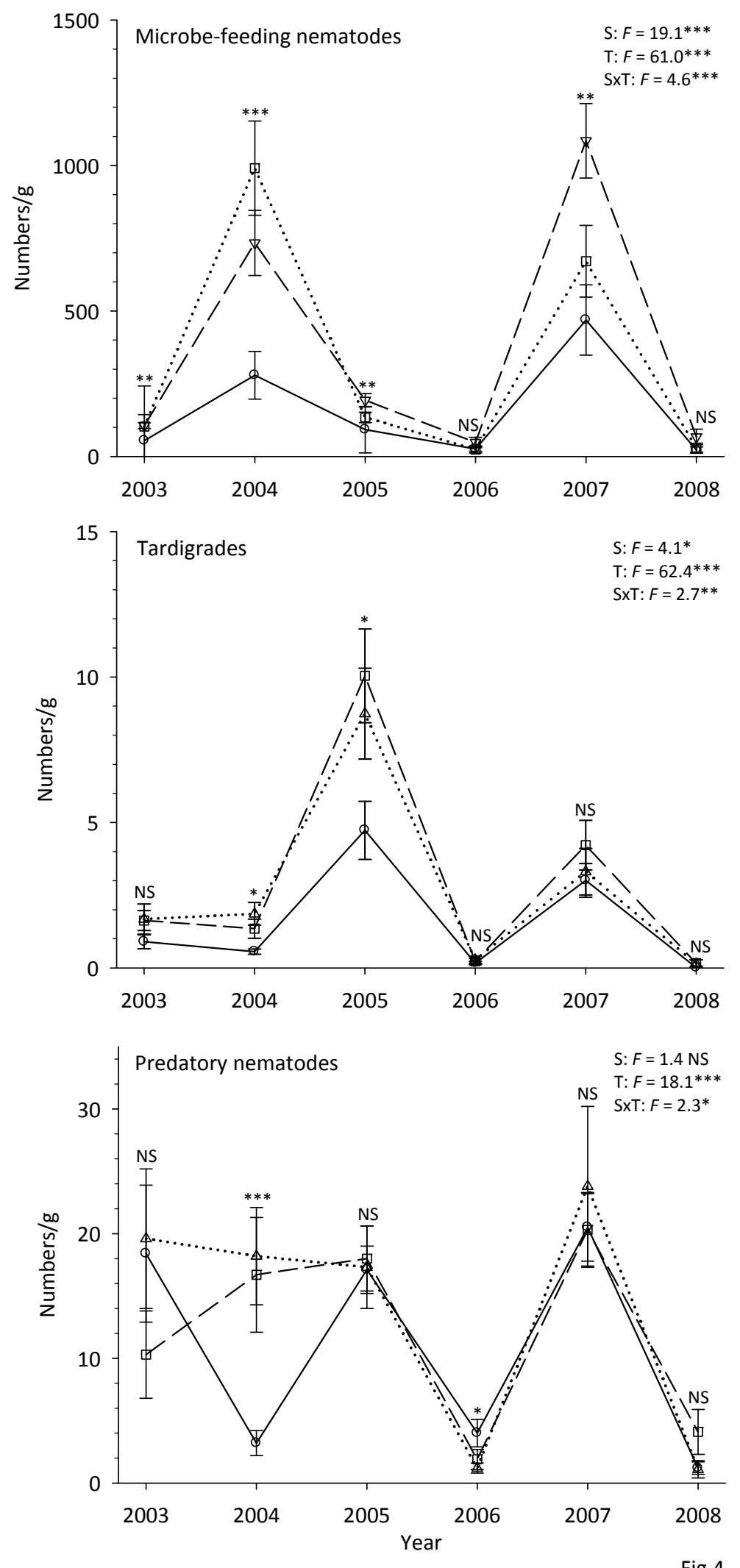

Fig.4 